\section{Noise and sports events}

To the Editor: I read the recent article on sound exposure during football matches in the SAMJ with great interest. ${ }^{1}$ Swanepoel et al. concluded that 'exposure levels exceeded limits of permissible average and peak sound ${ }^{1}$ and 'Public awareness and personal hearing protection should be prioritised as preventive measures'. ${ }^{1}$ It is interesting that sound from sports competitions could be an important forgotten noise. Indeed, sport noise-induced deafness has been proposed for years. ${ }^{2}$ The control of noise from competitions (e.g. control of audiovisual facilities) might be required; this would be more appropriate than having the spectators use protective devices.

\section{Viroj Wiwanitkit}

Bangkhae, Bangkok

Thailand

wviroj@yahoo.com

Swanepoel W, Hall JW. Football match spectator sound exposure and effect on hearing: A pretest-post-test study. S Afr Med J 2010; 100: 239-242.

2. Bentley S. Noise-induced deafness. Br J Sports Med 1978; 12: 160.

\section{Health technology assessment - a new initiative in South Africa}

To the Editor: From a clinical perspective, technology is expected to reduce the risk of disease, reduce duration of illness, improve quality of care, increase access and restore, or limit the decay of, a person's quality of life. Technology is also expected to contain costs and improve interventional risk management through enhancement of service efficiency and productivity of health care professionals. As health technology evolves, so does the need to assess its impact on patients' health outcomes, hospital operations, and financial resources. This process leads to the evolution of health technology assessment (HTA), which is a systematic evaluation of properties, effects and other consequences of health care technology. Its purpose is to provide objective information for supporting health care decisions and policy-making at international, national, provincial and health facility levels. An effective HTA programme produces good-quality information and analysis, and then effectively uses this information and knowledge to influence decision-makers in health care systems. ${ }^{1}$

The South African National Department of Health (DoH) published a policy paper on HTA in 1997. A steering committee was formed to drive the HTA agenda in South Africa, and a regulatory framework has been established under the National Health Act (Act No. 61 of 2003). Since then, little has been achieved in this field, although the importance of HTA was highlighted 10 years ago. ${ }^{2}$ Currently, only two universities in the country offer formal HTA programmes.

Against this backdrop, the Clinical Epidemiology Unit of the University of the Witwatersrand has initiated a translational research project to introduce HTA to public hospitals in South Africa. These hospitals spend a significant amount of resources, and there is an urgent need to develop their evidencebased decision-making processes in view of the impending introduction of national health insurance. The unit has established links with international organisations involved with HTA to create best practices in this field.

The unit has been working with several public hospitals' chief executive officers, who have been conducting research for their master's degrees in hospital management. Their areas of research include various components of HTA such as assessment of medical equipment, pharmaceuticals, blood and blood products, practice of clinical procedures, clinical governance and risk assessment (Fig. 1). These reports will be submitted to the national and provincial departments of health for the purposes of improving service delivery in South Africa's public hospitals.

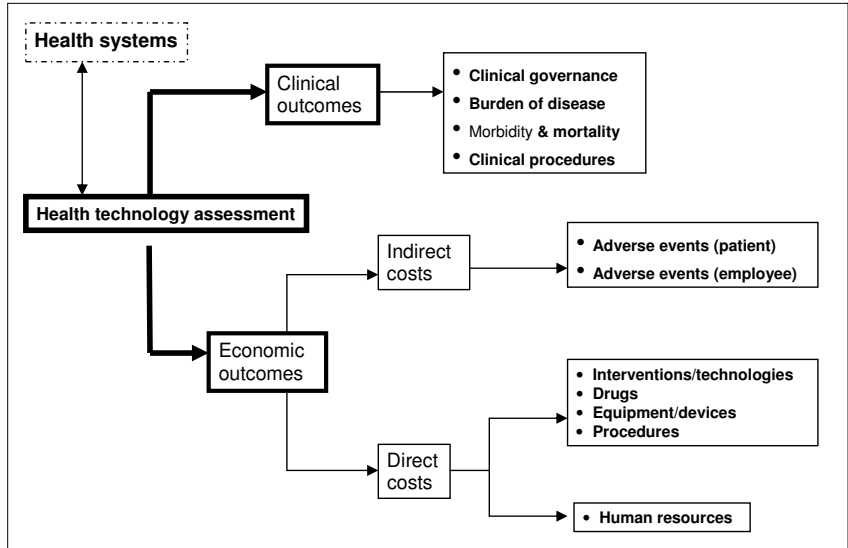

Fig. 1. Various components of health technology assessments currently studied in South African public hospitals.

\section{Moreshnee Govender}

School of Public Health

University of the Witwatersrand

Johannesburg and

Warmbaths Hospital

\section{Motlatso Elias Letshokgohla}

School of Public Health

University of the Witwatersand

\section{Debashis Basu}

Department of Community Health

University of the Witwatersrand and

Charlotte Maxeke Johannesburg Hospital

Debashis.Basu@wits.ac.za

1. International Network of Agencies for Health Technology Assessment. A Checklist for Health Technology Assessment Reports, 2001. http:/ /www.inahta.org (accessed 12 March 2010).

2. Kachieng'a MO, Boonzaier DA. Health care technology assessment - the South African health care system in transition. S Afr Med J 1999; 89(2): 149-155

\section{Clinical haematology training in South Africa for Fellows with the primary specialty of Internal Medicine - what's in a name?}

To the Editor: Clarity with regard to what training in clinical haematology in South Africa involves and aims to achieve can be elusive. Clinical haematology trainees can have primary specialties of Internal Medicine or Paediatrics or Pathology (Haematology). I discuss the situation of those with the primary specialty of Internal Medicine. 
In South Africa, clinical haematology combines clinical and laboratory haematology into one subspecialty. Regulation 11(1) of Government Notice No. R.590 of 29 June 2001 (Government Notice) ${ }^{1}$ states that a clinical haematologist shall have completed 4 years of training as a registrar in Medicine and then 2 years in Pathology (Haematological). In practice, interpretations vary.

The Clinical Haematology regulations of the College of Physicians $^{2}$ agree with the Government Notice $^{1}$ on who is a clinical haematologist $(\mathrm{CH})$. However, the regulations stipulate a clinical training component of 1 year and a laboratory training component of a minimum duration of 1 year, which differs from the apparent requirement of 2 years' training in the laboratory component. The regulations state that a $\mathrm{CH}$ should restrict himself/herself to treating adults with haematological disorders and can perform laboratory investigations within the scope of his/her training. The word 'restrict' may be interpreted to mean that the $\mathrm{CH}$ should restrict himself/ herself to adult patients rather than paediatric patients, or that a CH should restrict himself/herself to the clinical component of haematology. In contrast, the regulations for pathologists ${ }^{3}$ stick to the Government Notice and stipulate a 2-year clinical training component in either paediatrics or internal medicine. This makes the training and practice of clinical haematology for haematopathologists straightforward.

The regulations of the College of Physicians offer two possible interpretations to the training for clinical haematology, exemplified by the definitions of a haematologist in the USA and the UK. According to the American Society of Hematology (ASH), 'a hematologist is a physician who specializes in the diagnosis, treatment, prevention, and/or investigation of disorders of the hematopoietic, hemostatic, and lymphatic systems, and disorders of the interaction between blood and blood vessel wall'. ${ }^{4}$ The ASH therefore defines two types of haematologists: doctors who specialise in the clinical and laboratory aspects of haematology, and doctors who specialise in laboratory aspects. The ASH curriculum ${ }^{4}$ is intended for the former group but does not emphasise practical competency in laboratory haematology, which it presumably leaves to pathologists. ${ }^{5}$ The European Hematology Association (EHA), while maintaining the ASH definition of haematology, emphasises that a haematologist should have both clinical and technical laboratory competences ${ }^{6}$ and defines technical competence as the ability to carry out specific laboratory tests independently. However, the EHA acknowledges that European countries vary in terms of the profile and definition of a haematologist, with some countries considering haematopathology as part of haematology and others considering it a different specialisation. ${ }^{6}$ In the UK haematopathology is part of haematology and is not a separate specialisation. ${ }^{7}$

Some training institutions in South Africa may interpret clinical haematology according to the ASH and others may interpret it along the UK lines. The former institutions may believe that the 1 year of laboratory training in clinical haematology is not enough for physicians to achieve the competencies of a haematopathologist, while the latter institutions may provide physician clinical haematology trainees with laboratory rotations that provide graduated responsibilities including laboratory medicine calls.

\section{Yohannie Billy Mlombe}

Haematology Department

College of Medicine

University of Malawi

yohanniemlombe@googlemail.com

1. Health Professions Council of South Africa. Medical and dental regulations. http://www. hpcsa.co.za/downloads/medical_dental/Regulations/R.590_of_29_june_2001.pdf (accessed 31 January 2010).

2. College of Physicians: CMSA. http://www.collegemedsa.ac.za/Documents/doc_85.pdf (accessed 31 January 2010).

3. College of Pathologists: CMSA. http://www.collegemedsa.ac.za/Documents/doc_76.pdf (accessed 31 January 2010)

4. American Society of Haematology. Training. http://www.hematology.org/Training/ (accessed 31 January 2010)

5. Smith BR, Wells A, Alexander $\mathrm{CB}$, et al. Curriculum content and evaluation of resident competency in clinical pathology (Laboratory Medicine): a proposal. Clin Chem 2006; 52 compete

6. European Hematology Association. European Hematology Curriculum/Passport. http:// www.ehaweb.org/eha/media/files/education/european_hematology_curriculum_passport (accessed 31 January 2010).

7. A Career in Haematology. BMJ Careers. http://careers.bmj.com/careers/advice/view-article html?id=20000625 (accessed 31 January 2010) 